\title{
Cuidado seguro na administração de Penicilina G Benzatina em crianças com febre reumática: relato de experiência
}

Safe care in the administration of Penicillin G Benzathine in children with reumathic fever: experience report Atención segura en la administración de Penicilina G Benzatina en niños con fiebre reumatica: informe de experiencia

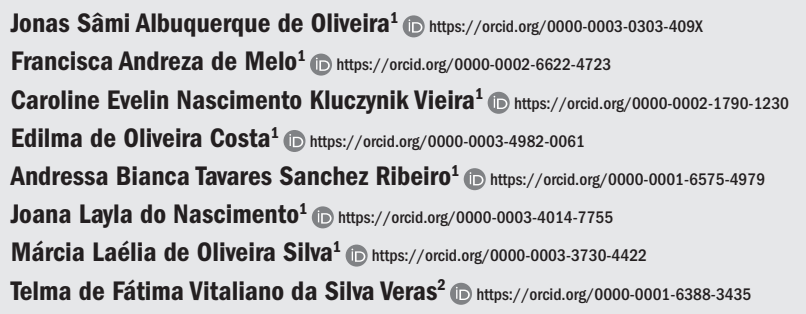

\section{Resumo}

Neste trabalho apresenta-se um relato de experiência no planejamento, organização, operacionalização e avaliação de um projeto de extensão desenvolvido no formato de um curso de capacitação para profissionais de saúde para promover 0 cuidado seguro na administração de penicilina $\mathrm{G}$ benzatina em crianças e adolescentes. 0 mesmo foi implementado no período de sete meses, com sete turmas com duração de quinze horas teórico-praticas. Participaram 233 profissionais e estudantes da área da saúde. Conclui-se que projetos de extensão envolvendo a comunidade são essenciais para promover melhores práticas em saúde, caracterizando-se como um projeto de grande importância social.

\section{Abstract}

This work presents an experience report in the planning, organization, operationalization and evaluation of a university extension project in the form of a training course for healthcare professionals to promote safe care on penicillin $\mathrm{G}$ benzathine administration in children and adolescents. The project was implemented on seven months with seven classes lasting fifteen theoretical-practical hours. 233 healthcare professionals and students participated. It is concluded that university extension projects involving the community are essentials to promote best practices in health, being characterized as a project of great social importance.

\section{Resumen}

Este trabajo presenta un informe en la planificación, organización, ejecución y evaluación de la un proyecto de extensión universitaria desarrollado en forma de un curso de capacitación para profesionales de la salud para promover la atención segura en la administración de penicilina $\mathrm{G}$ benzatina en niños y adolescentes. Lo mismo se implementó en el periodo de siete meses, con siete clases que duraron quince horas de teoría y práctica. Participaron 233 profesionales de la salud y estudiantes. Se concluye que los proyectos de extensión que involucran a la comunidad son esenciales para promover las mejores prácticas en salud, caracterizados como un proyecto de gran importancia social.

\section{Descritores}

Segurança do paciente; Enfermagem pediátrica. Educação permanente.

\section{Keywords}

Patient safety; Pediatric nursing;

Permanent Education

\section{Descriptores}

Seguridad del paciente; Pediatric enfermería; Educación permanente

\section{Como citar:}

Oliveira JS, Melo FA, Vieira CE, Costa EO, Ribeiro AB, Nascimento JL, et al. [Safe care in the administration of Penicillin G Benzathine in children with reumathic fever: experience report]. Rev Soc Bras Enferm Ped. 2019;19(2):111-21. Portuguese 


\section{Introdução}

A penicilina $G$ benzatina é um fármaco amplamente utilizado para o tratamento de diversas doenças infecciosas que acometem a criança e o adolescente. Esta medicação tem como característica ser extremamente dolorosa por se tratar de pó cristalino, com uma solubilidade extremamente baixa e consequente liberação lenta a partir do local de administração. Esta combinação de hidrólise e absorção lentas resulta em níveis séricos mais baixos, porém muito mais prolongados quando comparado às outras penicilinas de utilização parenteral. ${ }^{(1,2)}$

Os profissionais de saúde são desafiados em seu cotidiano de cuidado com a prescrição e administração desse medicamento por reconhecerem e se compadecerem com a dor inflingida à criança/adolescente e sua família, somada a administração unicamente por via intramuscular (IM), que exige do profissional além de habilidade técnica, conhecimentos de anatomia, farmacologia, interações e reações locais e sistêmicas após a aplicação, atentando ao risco de lesionar o nervo ciático, formação de hematomas, abscessos e necrose tecidual. ${ }^{(3)}$

Em relação às reações adversas à administração, a ocorrência de reações anafiláticas verdadeiras à penicilina é rara, ocorrendo em cerca de 0,01\% dos casos. No entanto, são comuns as reações do tipo vasovagais antes, durante e após a administração, associadas à dor ou a possibilidade de sensação dolorosa frente à administração. Estudos demonstraram, que o seguimento clínico, por mais de 3 anos, de pacientes em uso de penicilina $G$ benzatina para profilaxia de doença reumática, mostrou uma incidência de reações de 3,2\% e incidência de anafilaxia em 1,23/ 10.000 injeções. Reação fatal ocorreu em 1/32.000 injeções. ${ }^{(4-6)}$

O Ministério da Saúde promulgou em 27 dezembro 2011 a Portaria no 3.161 que dispõe sobre a administração da penicilina nas unidades de Atenção Básica à Saúde, no âmbito do Sistema Único de Saúde (SUS), considerando que sua administração é para o tratamento preconizado para doenças de relevante impacto em saúde pública, como febre reumática, sífilis, entre outras. Reforça no artigo $3^{0}$ que a administração da penicilina deve ser realizada pela equipe de enfermagem (auxiliar, técnico ou enfermeiro), médico ou farmacêutico. Desse modo, todos os profissionais devem estar capacitados para sua administração. ${ }^{(7)}$
Destaca-se nesse artigo a administração desse fármaco para a profilaxia e tratamento de febre reumática, que acomete predominantemente a criança na idade escolar, cujo primeiro ataque é raro antes dos 4 anos de idade e incomum após os 18 anos de idade, e a maior incidência acontece entre 5 e 15 anos de idade. ${ }^{(8)}$

Essa afecção se caracteriza como uma doença inflamatória e multissistêmica, que acomete aproximadamente $3 \%$ dos pacientes com faringite causada pelo microorganismo estreptococo beta-hemolítico do grupo A de Lancefield..$^{(9)}$ Devido ao diagnóstico e tratamento tardios, os pacientes podem evoluir para a doença estreptocócica aguda após uma a três semanas, e como consequência, apresentarem problemas $\operatorname{cardíacos}^{(10)}$ que se caracterizam, na maioria das vezes, por valvulite, em especial das valvas mitral e aórtica, que pode se cronificar e originar sequelas incapacitantes, em que um e dois terços dos indivíduos infectados por cepas de Streptococcus irão desenvolver cardite reumática. ${ }^{(11,12)}$

No que se refere ao tratamento e profilaxia da FR, o fármaco de primeira escolha que permite a erradicação e o controle das recorrências da doença é a penicilina $\mathrm{G}$ benzatina, ou benzilpenicilina benzatina, popularmente conhecida com o nome comercial de Benzetacil ${ }^{\circledR}$. Trata-se de um antibiótico de baixo custo e muito utilizada em virtude da sua alta eficácia em sua ação bactericida contra o estreptococcus. Este medicamento também é indicado para tratamento/profilaxia de outras doenças, tais como outras infecções estreptocócicas (do grupo A, sem bacteremia), infecções leves e moderadas do trato respiratório superior e da pele, sífilis, profilaxia da glomerulonefrite aguda, Coréia de Sydenham, dentre outras. ${ }^{(1,3)}$

Para a erradicação do estreptococo em casos de FR, a penicilina $G$ benzatina é utilizada em dose única. Para evitar novos surtos da febre reumática, indica-se esta medicação de maneira profilática, aplicando-se uma dose a cada 21 dias, até 21 anos ou até 5 anos após o último surto nos pacientes sem doença cardíaca, e até 25 anos ou 10 anos após o último surto, nos pacientes com febre reumática com cardite prévia, insuficiência mitral residual ou resolução da lesão valvar. Nos pacientes com lesão valvar residual moderada a severa, a profilaxia será mantida até a quarta década de vida ou por toda a vida. ${ }^{(9)}$

Devido a todas as características da medicação e das situações acima citadas, pode haver a mani- 
festação de temor por parte dos profissionais para sua administração, comprometendo a segurança do procedimento.

O projeto de extensão intitulado "Cuidado Seguro na Administração de Penicilina G Benzatina em Crianças e Adolescentes", foi demandado a partir da vivência prática de docentes, discentes e enfermeiros que atuam no ambulatório de pediatria de uma universidade pública da região nordeste, tendo em vista a necessidade crescente da administração da penicilina $G$ benzatina em crianças e adolescentes com diagnóstico médico de febre reumática. Dentre as dificuldades observadas identificaram o cenário de incerteza na administração da posologia integral da droga, as inúmeras queixas de familiares quanto aos traumas psicoemocionais em crianças, decorrentes de estresse com o momento da administração da droga, somado às queixas da equipe de enfermagem quanto à diluição da droga, a fim de evitar obstrução de agulha, assim como o absenteísmo e desistência terapêutica de crianças e adolescentes e de suas famílias.

Diante disso, propôs-se um projeto de extensão para promover ação de educação permanente aos profissionais de saúde e da equipe de enfermagem dos níveis médio e superior que atuam na assistência a crianças e adolescentes, com a finalidade de minimizar as dúvidas relativas às principais dificuldades no cuidado às crianças com febre reumática, em especial no tocante à garantia da administração segura da droga padrão do tratamento.

Com isso, ressalta-se a importância da universidade no contexto da extensão enquanto integrador do ensino/serviço, incentivando propostas que contribuam para assistência prestada pelos serviços de saúde.

Neste contexto, o objetivo é relatar a experiência do planejamento, organização, operacionalização e avaliação de um projeto de extensão universitária.

\section{Métodos}

Trata-se de um relato de experiência de um projeto de extensão denominado "Cuidado seguro na administração de Penicilina G Benzatina em crianças e adolescentes".

A seguir apresenta-se o planejamento, a operacionalização e avaliação do referido projeto.

\section{0 projeto de extensão: Cuidado seguro na administração de Penicilina G Benzatina em crianças e adolescentes}

O projeto foi desenvolvido e implementado na Universidade Federal do Rio Grande do Norte (UFRN), pelo Departamento de Enfermagem em colaboração com o Departamento de Pediatria, sendo financiado pela Pró-Reitoria de Extensão (PROEX) da mesma universidade.

Baseou-se nos fundamentos da educação permanente para promover o desenvolvimento de consciência crítica e reflexiva dos profissionais de saúde sobre o seu contexto de trabalho. Vale salientar que se considerou um processo sistematizado e participativo, assim como o espaço de trabalho, como local fundamental para trabalhar e aprender. Nesse sentido, a dialética foi o referencial teórico-filosófico adotado, pelo motivo da práxis dos profissionais da enfermagem, assim como pela consideração das transformações das relações sociais e dos processos de trabalho e vida existentes no cotidiano. ${ }^{(13)}$

O público-alvo foram os enfermeiros, técnicos de enfermagem e auxiliares de enfermagem que trabalham com criança e adolescente na atenção primária e na rede hospitalar, assim como estudantes de cursos de nível técnico e superior em enfermagem e nas áreas de farmácia e medicina.

Apresentou o objetivo de proporcionar um espaço de aprendizagem aos profissionais de enfermagem e estudantes da área da saúde para a administração segura de penicilina $G$ benzatina às crianças e adolescentes com febre reumática.

No planejamento foi conduzida uma revisão da literatura acerca dos métodos utilizados pelo serviço de saúde pediátrico para o cuidado de enfermagem na administração de penicilina $\mathrm{G}$ benzatina em crianças e adolescentes com FR.

Para a operacionalização foi proposto um curso de capacitação, realizado no período de maio a novembro de 2019, replicado nas últimas sextas-feiras de cada mês, contemplando turmas diferentes entre trinta e cinquenta profissionais e estudantes. Buscou-se financiamento da universidade através de recursos da PROEX, o qual foi obtido para a realização do projeto.

A equipe executora foi composta por docentes do departamento de enfermagem da UFRN, enfermeiros 
dos serviços de saúde, alunos bolsistas e parceiros dos serviços.

Para a divulgação, os participantes foram convidados através de contato com os profissionais de saúde, por enfermeiros que a frente de suas equipes, e pela divulgação em mídias sociais, como WhatsApp ${ }^{\circledR}$ e Instagram ${ }^{\circledR}$. Todas estas formas de divulgação auxiliaram na captação dos profissionais que precisavam desta capacitação, daqueles que possuem interesse na área de saúde da criança e do adolescente, e dos estudantes de enfermagem de cursos de nível médio e de nível superior.

A inscrição foi realizada pela internet através do Sistema Integrado de Gestão de Atividades Acadêmicas (SIGAA), atual sistema de comunicação da universidade. Um documento detalhando sobre os procedimentos para a inscrição online no curso (tanto aos alunos como não-alunos da UFRN), para preencher as vagas destinadas ao mês em questão, ocorrendo a seleção por ordem de inscrição, dando preferência a quem já trabalha na área.

A finalidade do curso foi a colaboração formativa a fim da redução de diferentes dúvidas relacionadas ao preparo e a administração da penicilina $G$ benzatina em crianças e adolescentes com febre reumática que utilizam esta medicação e proporcionar aprofundamento no relacionado à doença reumática. Adotouse a modalidade teórico-prática sendo a parte teórica (turno matutino) e a prática (turno vespertino).

A carga horária total foi de quinze horas, divididas em teoria (10 horas) e prática (5 horas). No que se refere às atividades teóricas, foram disponibilizados referências bibliográficas para leitura prévia enviadas via correio eletrônico aos participantes, o que conferiu a carga horária de cinco horas para estudo e cinco horas em discussão presencial em sala de aula, sendo a parte teórica (turno matutino) e a prática (turno vespertino).

O alicerce teórico do curso foi composto pela síntese das evidências científicas sobre o fármaco, as técnicas de analgesia, o preparo e a administração. Tais materiais possuem evidência nacional e internacional sobre a temática, tal como o British Medical Journal Best Practice, que traz atualizações sobre a FR, uma revisão de literatura acerca do diagnóstico da FR e um capítulo de livro que aborda as técnicas de analgesia (farmacológica e não farmacológicas). ${ }^{(2,12)}$

O conteúdo teórico foi ministrado tanto pelo coordenador do curso, como também por enfermeiros envol- vidos em outros projetos de extensão como o da febre reumática em crianças e adolescentes, por enfermeiros do ambulatório pediátrico da UFRN, e com a participação de residentes de enfermagem em saúde da criança e do adolescente pela UFRN, cuja atuação é no Hospital Universitário Onofre Lopes (HUOL). Além disso, de forma complementar, também houve a participação de uma profissional médica, especialista em cardiopediatria, docente do curso de medicina da UFRN, coordenadora do projeto de extensão da febre reumática.

Em relação às atividades práticas, os participantes foram divididos igualmente em grupos, conforme número de presentes, garantindo que todos tivessem oportunidade de rodiziar em quatro estações, com duração de trinta minutos cada. As estações foram distribuídas em seguintes temas: acolhimento às crianças e adolescentes com febre reumática, técnicas de analgesia na administração da penicilina $G$ benzatina, preparo da medicação e administração do medicamento. Ressalta-se que as duas últimas estações eram realizadas em laboratório de simulação realística garantindo-se o manejo da penicilina $G$ benzatina e sua administração em manequins pediátricos e adultos.

Cada estação contou com um fluxograma referido ao assunto tratado, de maneira que os participantes pudessem compreender as ações de cuidado às crianças e adolescentes com febre reumática. Estes fluxogramas foram produzidos pelos participantes de um programa de extensão da universidade denominado "Programa de enfermagem às crianças e adolescentes com febre reumática e cardiopatia reumática em uso de benzilpenicilina benzatina", coordenado pelo professor responsável por este projeto do curso, docente do curso de enfermagem da UFRN, e que autorizou o uso dos mesmos durante o curso, a fim de manutenção da didática de forma clara e dinâmica.

A seguir apresenta-se a dinâmica realizada em cada uma das quatro estações práticas:

\section{Acolhimento a crianças e adolescentes com febre reumática na administração de benzilpenicilina benzatina (Anexo 1)}

Nesta estação, os participantes se aperfeiçoam no acolhimento de crianças que possuem o diagnóstico de febre reumática e estão em acompanhamento quanto a profilaxia por meio da administração da medicação. 
São orientados a verificar a caderneta de controle da medicação prescrita, observando a regularidade das doses administradas, o estágio da doença, a regularidade das consultas e os exames laboratoriais realizados.

A pesagem da criança deve acontecer a cada consulta, pois a posologia da droga deve estar relacionada e adequada ao seu peso (1.200.000 UI ou 600.000 UI). Nas situações em que a posologia prescrita estivesse diferente do peso corpóreo da criança, recomenda-se o retorno ao profissional médico para a correção. Em seguida o profissional de enfermagem precisa atentar para a realização do aprazamento para a nova administração, contados 21 dias dessa administração.

Com estes conhecimentos adquiridos, ao verificar uma prescrição médica acerca da administração da Penicilina G benzatina, os profissionais puderam identificar as situações em que deveriam orientar o retorno ao atendimento médico para correções acerca de posologias, ou de outra informação equivocada e a realizar o aprazamento dentro do período correto. Ressaltou-se também a importância da orientação à criança ou adolescente e do seu familiar acompanhante em relação aos procedimentos de preparo, administração e técnicas de analgesia.

\section{Técnicas de analgesia na administração da Penicilina $\mathrm{G}$ benzatina em crianças e adolescentes (Anexo 2)}

Objetivou-se com esta estação, a discussão e o aprofundamento acerca das técnicas de analgesia relacionadas ao uso da Penicilina G benzatina, tal como a troca de experiência entre os profissionais quanto a redução da dor, questionando aos inscritos se estes já haviam aplicado alguma dessas técnicas ou outra diferente e qual tentariam realizar, para ajudar as crianças e os adolescentes a não abandonarem seu tratamento devido a dor.

As técnicas discutidas foram as farmacológicas e as não farmacológicas. A técnica farmacológica envolve o uso da lidocaína em diferentes concentrações, em que a lidocaína a $1 \%$ vai ser utilizada para a diluição da penicilina $G$ benzantina, enquanto a $2 \%$ vai ser utilizada apenas no bisel da agulha, aspirando cerca de 0,25 ml. Foi esclarecido que o uso da lidocaína exige prescrição médica, tanto para utilização na diluição, como no bisel da agulha. ${ }^{(2)}$
Os métodos não farmacológicos no alívio da dor discutidos foram a crioterapia, pressão manual, além do aparelho vibratório com sensibilidade térmica denominado Buzzy ${ }^{\mathrm{TM}}$. A crioterapia consiste no uso de mecanismos resfriadores que reduz a temperatura dos tecidos com finalidade terapêutica de diminuir a dor local. ${ }^{(15,16)}$ No uso da Penicilina G benzatina recomenda-se a aplicação de uma compressa fria, por aproximadamente 10 segundos, antes da administração da medicação, tal como a pressão manual, que consiste na pressão com o polegar no local de aplicação, até sentir resistência, antes de realizar a técnica de administração. Ambas podem ser utilizadas sem prescrição médica, porém é preciso do consentimento da criança e do familiar que a acompanha. ${ }^{(2)}$

\section{Preparo da Penicilina G Benzatina para crianças e adolescentes (Anexo 3)}

Orientados por professores do departamento e por enfermeiros, os participantes puderam realizar o preparo da medicação, tanto no referente à diluição em água bidestilada ou lidocaína a 1\% (em caso de analgesia farmacológica prescrita pelo profissional médico), como a troca de agulhas para a administração e agitação vigorosa do conteúdo no frasco-ampola da penicilina, até a homogeneização completa da solução.

Detalhadamente, o profissional deve separar o material a ser utilizado (seringa descartável de $5 \mathrm{ml}$, agulha para aspiração $40 \times 12$ ou $25 \times 7$, agulha para administração $25 \times 7$ ou $25 \times 8$, frasco ampola da penicilina, ampola de água bidestilada, algodão, álcool, luva de procedimento e lidocaína, se esta tiver sido prescrita).

Após isso, deve acoplar a agulha para aspiração na seringa e aspirar o conteúdo de água bidestilada (ABD) ou lidocaína, que deverá ser em torno de 2,5 a 3,2 ml. Em seguida, retira-se o lacre da parte superior do frasco-ampola de penicilina, higienizando com algodão embebido com álcool, antes se injetar o conteúdo da seringa no frasco. Após o conteúdo da seringa estar dentro do frasco, deve-se agitar vigorosamente até a completa homogeneização da solução, pois a não dissolução completa, poderá acarretar em dor à criança/adolescente e possível formação de abscesso.

Foram revisados também os nove certos da administração segura de medicamentos, tais como o medicamento certo, paciente certo, dose certa, via 
certa, horário certo, registro certo, ação certa, forma farmacêutica certa e monitoramento certo. Todos estes certos, atrelados ao uso de equipamento de proteção individual (EPI) e higienização das mãos, ajudam na segurança do paciente no referente a administração correta da Penicilina G benzatina.

\section{Administração de Penicilina G Benzatina em crianças e adolescentes (Anexo 4)}

Nesta estação os participantes revisaram os procedimentos relativos à administração via intramuscular (IM), com ênfase na escolha dos sítios dorso glúteo e ventroglúteo. Cabe atenção especial quanto à resistência dos familiares na administração na área do ventroglúteo em crianças, o que precisa ser avaliado pela equipe de enfermagem, pois as condições gerais da massa muscular podem apresentar variações posto que, há uma frequência significativa de crianças com FR com moderados casos de desnutrição. Nesse sentido, a musculatura de escolha para a administração precisa ser adequada para acomodar o volume e posologia prescrita com segurança para as crianças. ${ }^{(13-16)}$

Novamente se discutiu os quesitos dos nove certos na administração medicamentosa, além da garantia da privacidade do paciente e posições confortáveis para administração que devem ser oferecidas e discutidos com o paciente, mostrando que pode ser deitado, em posição dorsal, com pés voltados para dentro ou em pé, com perna levemente flexionada, onde os pés também estão voltados para dentro.

Além disso, orientou-se quanto a interrupção do fluxo (obstrução) durante a administração, no qual se deve agitar vigorosamente a seringa, sobre o que fazer em relação a casos com reações vasovagais e reações anafiláticas, quando se deve solicitar atendimento médico de urgência.

\section{Resultados}

Foram realizadas sete edições do curso, com 233 participantes, dentre esses auxiliares e técnicos de enfermagem, enfermeiros, e estudantes desses níveis, de forma a também oferecer a estes, acesso a qualificação, que poderá auxiliá-los futuramente, ou durantes seus estágios curriculares. Muitos dos que estavam na gradua- ção em enfermagem já possuíam certificado de curso técnico em enfermagem e atuantes na área, fazendo-se necessário esta atualização. Além disso, foram capacitados estudantes de cursos de farmácia e de medicina também.

Nestes sete meses de experiência com o projeto de extensão, quando questionado aos participantes acerca de suas motivações iniciais, a maioria referia "adquirir conhecimento teórico e prático sobre a temática", "aperfeiçoamento", "desmistificar os tabus referente à penicilina $G$ benzatina e conhecer especificidades do público infanto-juvenil", "interesse na área de pediatria", "sentir segurança na administração".

No que se refere à implementação do curso, as atividades teóricas foram fundamentais para subsidiar a discussão para várias temáticas, tais como a prevenção de doenças cardíacas na pediatria, o que é Febre Reumática, farmacologia da penicilina G benzatina, sua formulação, mecanismo de ação, efeitos adversos, reações vasovagais, anafilaxia, preparo e administração. Esta também possibilitou aos alunos tiraram suas dúvidas e falarem sobre suas experiências. Evidenciou-se a necessidade de aprofundar o ensino sobre a administração de penicilina de maneira mais detalhada durante a graduação e a importância do conhecimento da fisiopatologia da doença, considerando que os profissionais se inscreveram em busca de qualificação, mas sem imaginar que muitos cuidados deveriam ser tomados durante o tratamento da FR com a penicilina $G$ benzatina.

A implementação do projeto de extensão com a participação de profissionais de áreas afins ministrando o curso e a troca de informações, experiências e vivências entre todos os participantes, foi essencial, pois permitiu um espaço formativo rico em saberes e em conhecimento. Nesse contexto, os encontros permitiram trocar várias experiências e conhecimentos entre os profissionais que já atuavam na área, com aqueles que já usaram a penicilina como terapêutica, dentre outros, potencializando o conhecimento a ser adquirido devido às diferentes realidades vivenciadas pelos participantes e das concepções teóricas que permeiam a temática.

Importante ressaltar que mesmo para um enfermeiro que não trabalhe na área pediátrica é importante aprender e aprimorar os conhecimentos relacionados à temática, haja visto a incidência de casos e a impor- 
tância de um cuidado seguro de modo a garantir um tratamento efetivo a esses pacientes.

A experiência proporcionou aos participantes o aprofundamento acerca do fármaco tanto no âmbito teórico como prático, com uma base mais consistente e embasada, de maneira a se tornarem aptos e seguros na sua administração.

Pode-se citar com fatores limitantes, a impossibilidade de participação de todos os profissionais de enfermagem, ficando restrito a um profissional por equipe. Dessa maneira, o mesmo ficou responsável por adquirir os conhecimentos e repassar aos colegas de trabalho. Isto indica a necessidade de ampliar a oferta de cursos dessa natureza, assim como buscar novas estratégias para garantir a todos a oportunidade da educação permanente nos serviços de saúde.

\section{Conclusão}

Conclui-se que o projeto de extensão atingiu seu objetivo de proporcionar um espaço para qualificação para o cuidado seguro na administração de penicilina $\mathrm{G}$ benzatina. A metodologia aplicada foi avaliada de maneira positiva pelos participantes, devido a maneira dinâmica do processo ensino-aprendizagem, tanto do conteúdo teórico quanto prático. A dinâmica das estações práticas facilitou ao profissional se apropriar do conhecimento, combinando de maneira didática a realidade prática dos espaços das salas de administração de medicações dos serviços de saúde. Dentre os aspectos positivos, o curso atingiu 233 profissionais e estudantes da área da saúde que vivenciaram a aproximação inicial e aprimoraram as inquietações e dúvidas sobre a administração do medicamento em crianças e adolescentes com febre reumática. Espera-se que os participantes possam disseminar os conhecimentos adquiridos neste projeto de extensão, contribuindo para a administração segura da penicilina $G$ benzatina, não apenas no tratamento da FR, como também em outras situações em que se utiliza esta medicação como escolha terapêutica. Cabe destacar ainda o impacto social que o projeto alcançou, ressaltando-se aqui a importância da universidade apoiar projetos dessa natureza.

\section{Referências}

1. Benzetacil (Benzilpenicilina benzatina). [bula]. São Paulo: Eurofarma Laboratórios S.A; 2014.

2. Ribeiro AB, Oliveira JS, Costa E0, Leite GC, Veras TF. Penicilina G Benzatina no tratamento da febre reumática: revisão da administração e das técnicas de analgesia. 3a ed. João Pessoa (PB): Instituto Medeiros de Educação Avançada - IMEA; 2019. p694.

3. Barbosa PJ, Muller RE, Latado AL, Achutti AC, Ramos AlO, Weksler C, et al. Diretrizes Brasileiras para Diagnóstico, Tratamento e Prevenção da Febre Reumática da Sociedade Brasileira de Cardiologia, da Sociedade Brasileira de Pediatria e da Sociedade Brasileira de Reumatologia. Arq Bras Cardiol. 2009;93(3 supl.4):1-18.

4. Rosário NA, Gumach AS. Allergy to beta-lactams in pediatrics: a practical approach. J Pediatr. 2006;82(5 Suppl):S181-8.

5. Greenberger PA. Drug allergy. J Allergy Clin Immunol. 2010;125(2 Suppl 2):464-70.

6. Markowitz M, Lue HC.Allergic reactions in rheumatic fever patients on long-term benzathine penicillin G: the role of skin testing for penicillin allergy. Pediatrics. 1996;97(6 Pt 2):981-3.

7. Brasil. Ministério da Saúde. Portaria 3161/2011. Dispõe sobre a administração da penicilina nas unidades de Atenção Básica à Saúde, no âmbito do Sistema Único de Saúde. Brasilia (DF): Ministério da Saúde; 2011.

8. Bertoletti JC. Profilaxia da febre reumática: quando e como fazer. Rev Soc Cardiol do Rio Grande do Sul. 2004;1(10):1-2.

9. Goldenzon AV, Rodrigues MC, Diniz CC. Febre reumática: revisão e discussão dos novos critérios diagnósticos. Rev Pediatr SOPERJ. 2016;16(3):30-35.

10. Henningham A, Barnett TC, Maamary PG, Walker MJ. Pathogenesis of group a streptoccocal infections. Discov Med 2012;13(72):329-42.

11. Costa LP, Domiciano DS, Pereira RM. Características demográficas, clínicas, laboratoriais e radiológicas da febre reumática no Brasil: revisão sistemática. Rev Bras Reumatol. 2009;49(5):606-16.

12. Pereira $B A$, Belo $A R$, Silva NA. Febre reumática: atualização dos critérios de Jones à luz da revisão da American Heart Association \2015. Rev Bras Reumatol. 2017;57(4):364-368.

13. Chasin J. Marx: estatuto ontológico e resolução e metodológica [nota em posfácio]. São Paulo: Boitempo; 2009.

14. Knight KL. Crioterapia no tratamento das lesões esportivas. São Paulo: Manole; 2000.

15. Francisco AM, Oliveira SMJV, Leventhal LC, Bosco CS. Crioterapia no pós-parto: tempo de aplicação e mudanças na temperatura perineal. Rev Esc Enferm USP 2013;47(3):555-61.

16. Hockenberry MJ, Wilson D. Wong - fundamentos da enfermagem pediátrica. 9a ed. Rio de Janeiro: Elsevier; 2014. 


\section{FLUXOGRAMA I: ACOLHIMENTO A CRIANÇAS E ADOLESCENTES COM FEBRE REUMÁTICA NA ADMINISTRAÇÃO DE PENICILINA G BENZATINA}

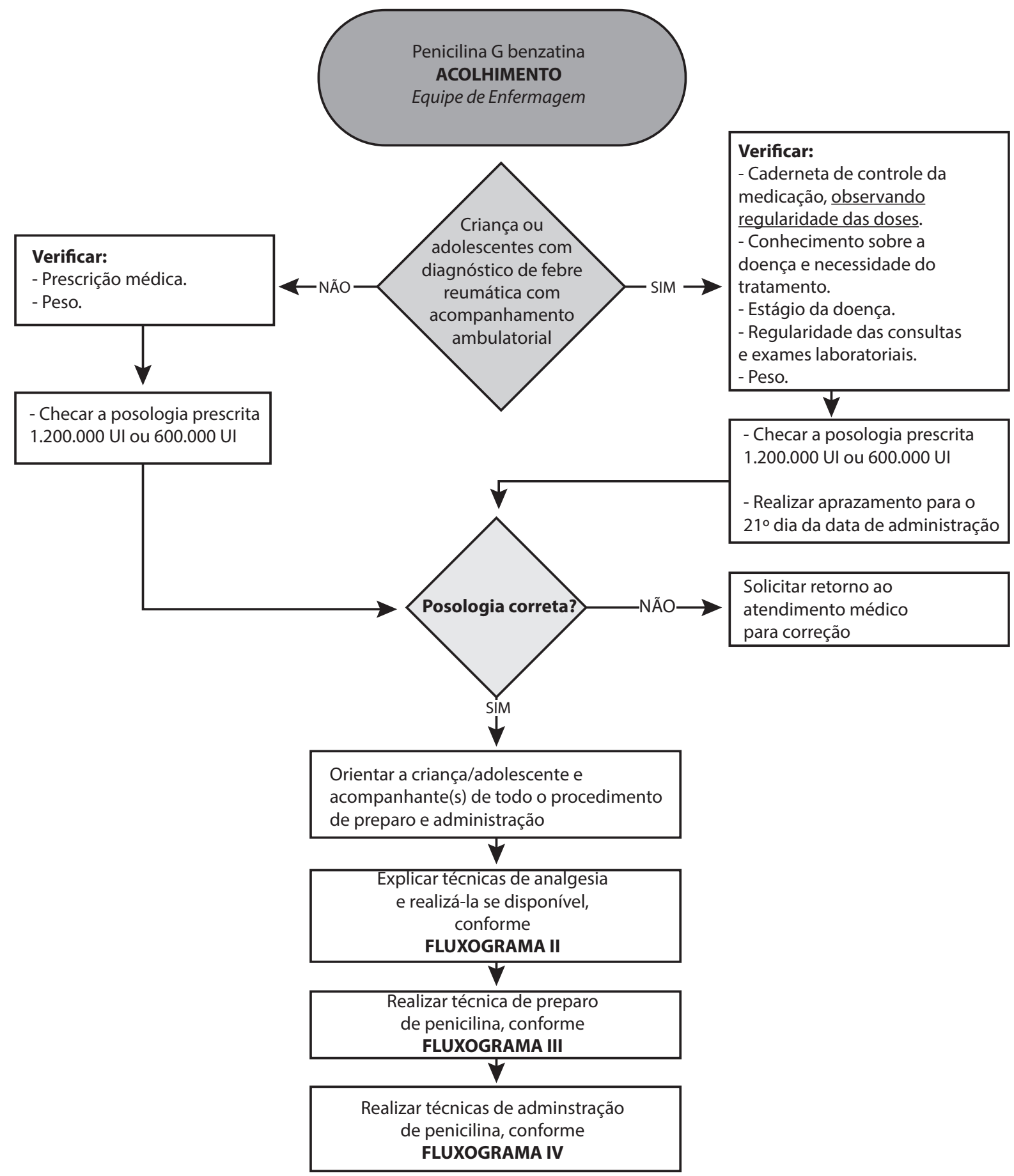

\section{REFERÊNCIAS:}

ALMEIDA, F. A.; SABATÉS, A. L. (Org). Enfermagem pediátrica: a criança, o adolescente e sua família no hospital. São Paulo: Manole, 2008, p. 193-200. BRASIL. Sociedade Brasileira de Cardiologia. Diretrizes brasileiras para o diagnóstico, tratamento e prevenção da febre reumática. Arq. bras. Cardiol. v. 93 (3, supl.4), p. 3-18, set. 2009. Disponível em: http://dx.doi.org/10.1590/S0066-782X2009002100001. Acesso em: 10 set. 2018.

Anexo 1. Acolhimento a crianças e adolescentes com febre reumática na administração de Penicilina G Benzatina 


\section{FLUXOGRAMA II: TÉCNICAS DE ANALGESIA NA ADMINISTRAÇÃO DE PENICILINA G BENZATINA EM CRIANÇAS E ADOLESCENTES}

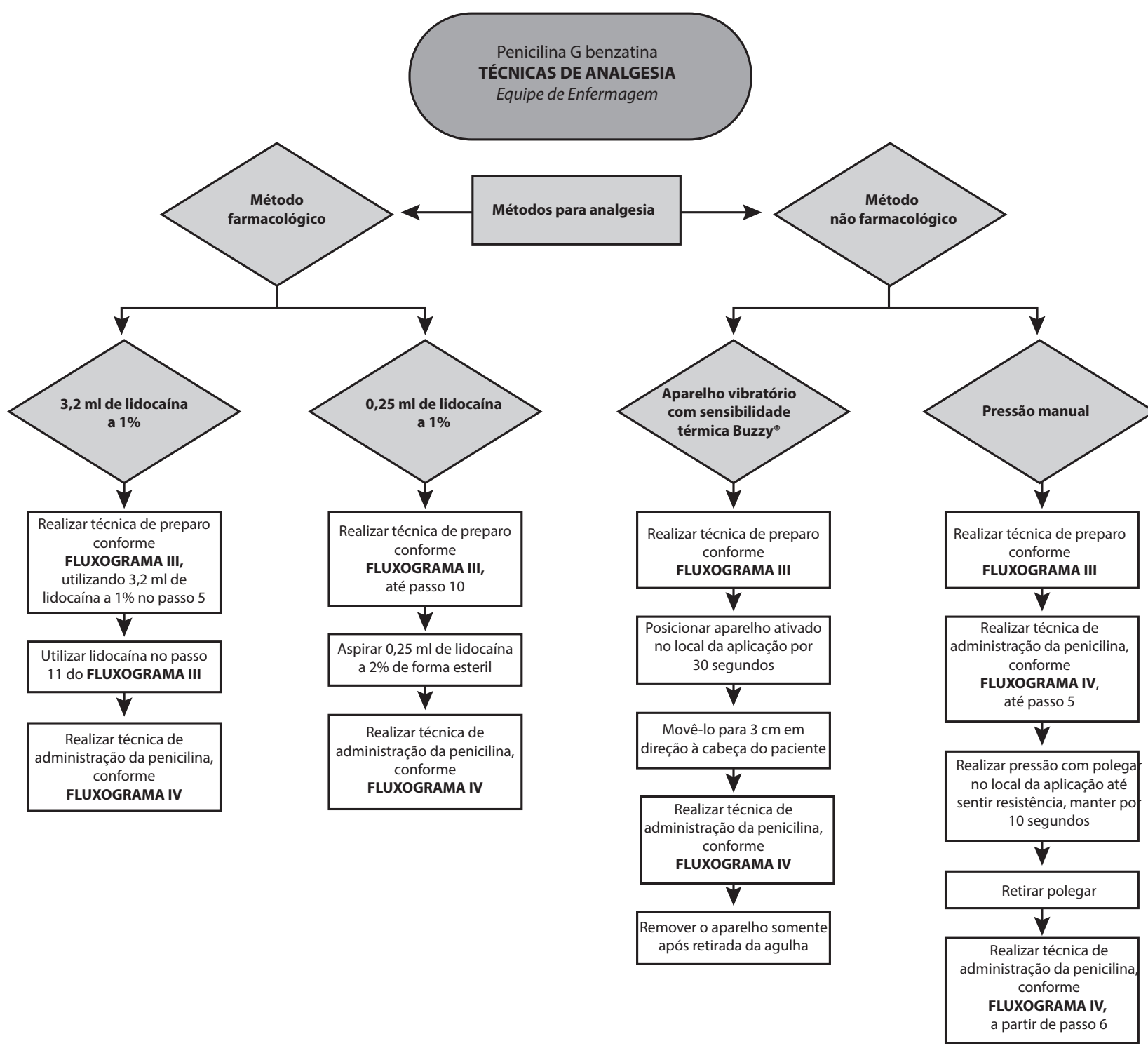

\section{REFERÊNCIAS:}

AMIR, J. M. D. et al. Lidocaine as diluent for administration of benzathine penicillin G. The Pediatric Infectious Disease Journal Issue. v.17(10), p. 890-893, out. 1998. Disponível em: https://insights.ovid.com/pubmed?pmid=9802630. Acesso em: 10 set. 2018

DERYA, E. Y. et al. Applying Manual Pressure before Benzathine Penicillin Injection for Rheumatic Fever Prophylaxis Reduces Pain in Children. Pain Management Nursing. v.16, n.3, p. 328-335, jun. 2015. Disponível em: http://dx.doi.org/10.1016/.pmn.2014.08. 013 Acesso em: 08 set. 2018.

MORSY, M. M. F. et al. Lidocaine as a Diluent for Benzathine Penicillin G Reduces Injection Pain in Patients with Rheumatic Fever: a Prospective, Randomized Double-Blinded

Crossover Study. Australian Journal of Basic and Applied Sciences. v.6(5), p. 236-240, 2012. Disponível em: https://www.ncbi.nlm.nih.gov/pubmed/9802630. Acesso em: 10 set. 2018.

RUSSEL, K.; NICHOLSON, R.; NAIDU, R. Reducing the pain of intramuscular benzathine penicillin injections in the rheumatic fever population of Counties Manukau District Health Board. Journal of Paediatrics and Child Health. v.50, p.112-117, 2014). Disponível em: doi:10.1111/jpc.12400. Acesso em: 10 set. 2018.

Anexo 2. Técnicas de analgesia na administração de Penicilina G Benzatina em crianças e adolescentes 


\section{FLUXOGRAMA III: PREPARO PENICILINA G BENZATINA PARA CRIANÇAS E ADOLESCENTES}

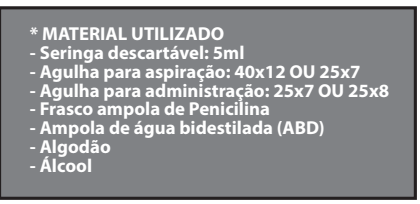

**9 CERTOS DA ENFERMAGEM 1 Mediçáo certa 3 Dose certa 4 Via certa 5 Horário certo 6 Registro certo 7 Açăo certa 8 Forma farmacêutica cert

\section{***De acordo com a massa muscular e} idade do paciente

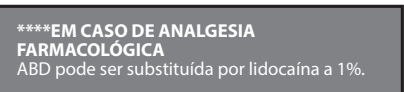

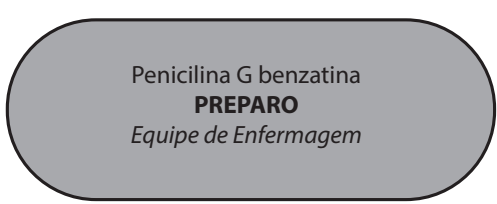

1. Separar todo o material a ser utilizado*

\section{4}

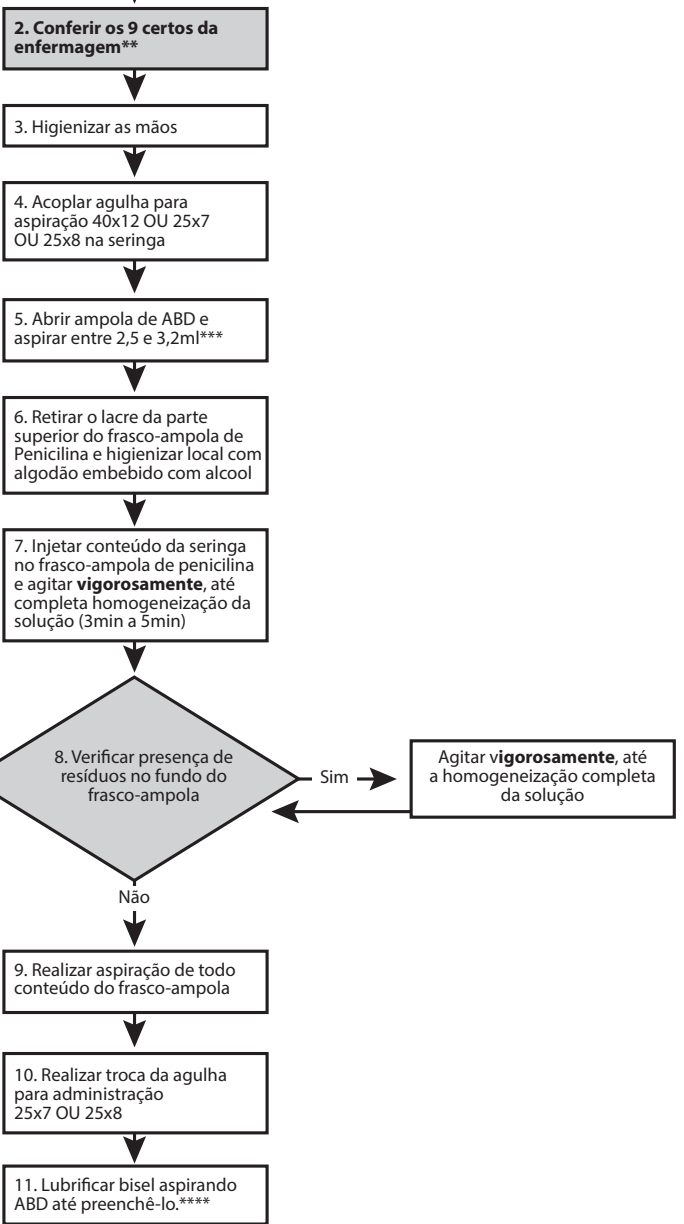

REFERÊNCIAS:

AMIR, J. M. D. et al. Lidocaine as diluent for administration of benzathine penicillin G. The Pediatric Infectious Disease Journal Issue. v.17(10), p. 890-893, out. 1998. Disponível em: https://insights.ovid.com/pubmed?pmid=9802630. Acesso em: 10 set. 2018.

BRASIL. Ministério da Saúde. ANVISA. Protocolo de segurança na prescrição, uso e administração de medicamentos. Brasília (DF). 2013. Disponível em: http://www.hospitalsantalucinda.com.br/downloads/prot_meficamentos.pdf. Acesso em: 10 set. 2018.

CAMPINAS. Secretaria Municipal de Saúde. ORIENTAÇÕES PARA USO DE PENICILINA BENZATINA ASSOCIADA A LIDOCAÍNA 2\% PARA GESTANTES COM SÍFILIS E SEUS PARCEIROS - SMS CAMPINAS 001-2017. Junho, 2017. Disponível em: http://www.saude.campinas.sp.gov.br/programas/protocolos/protocolo_mulher/2017/Nota_Tecnica_001_ 2017_Protocolo_de_Uso_de_Penicilina_Benzatina_associada_a_Lidocaina_para_Gestantes_com_Sifilis_e_Parceiros.pdf. Acesso em: 10 set. 2018.

MORSY, M. M. F. et al. Lidocaine as a Diluent for Benzathine Penicillin G Reduces Injection Pain in Patients with Rheumatic Fever: a Prospective, Randomized Double-Blinded Crossover Study. Australian Journal of Basic and Applied Sciences. v.6(5), p. 236-240, 2012. Disponível em: https://www.ncbi.nlm.nih.gov/pubmed/9802630. Acesso em: 10 set. 2018.

RUSSEL, K.; NICHOLSON, R.; NAIDU, R. Reducing the pain of intramuscular benzathine penicillin injections in the rheumatic fever population of Counties Manukau District Health Board. Journal of Paediatrics and Child Health. v.50, p.112-117, 2014). Disponível em: doi:10.1111/jpc.12400. Acesso em: 10 set. 2018.

Anexo 3. Preparo Penicilina G Benzatina para crianças e adolescentes 


\section{FLUXOGRAMA IV: ADMINISTRAÇÃO DE PENICILINA G BENZATINA EM CRIANÇAS E ADOLESCENTES}

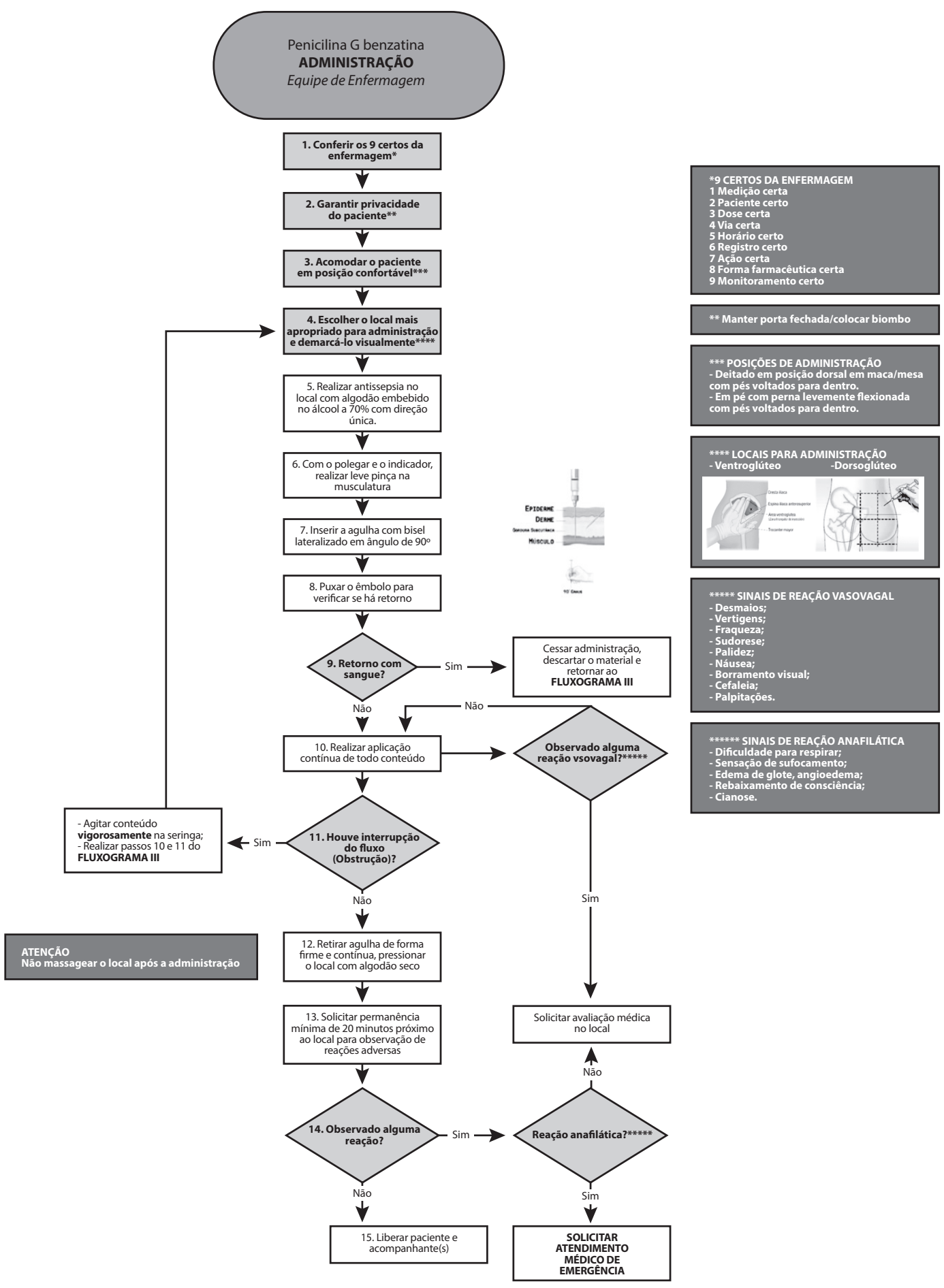

REFERÊNCIAS:

ALMEIDA, F. A.; SABATÉS, A. L. (Org). Enfermagem pediátrica: a criança, o adolescente e sua família no hospital. São Paulo: Manole, 2008, p. 193-200.

BRASIL. Ministério da Saúde. ANVISA. Protocolo de segurança na prescrição, uso e administração de medicamentos. Brasília (DF). 2013. Disponível em:

http://www.hospitalsantalucinda.com.br/downloads/prot_meficamentos.pdf. Acesso em: 10 set. 2018.

OLIVEIRA, L. F. et al. Ensaio clínico controlado randomizado: região ventro glútea, local alternativo para aplicação da benzilpenicilina benzatina G.

Rev. Eletr. Enf. 1v7(4). out./dez. 2015. Disponível em: http://dx.doi.org/10.5216/ree.v17i4.29612. Acesso em: 01 out. 2018.

POTTER, P.; PERRY, A.G. Fundamentos de Enfermagem. 8. ed. Rio de Janeiro: Elsivier, 2013. p 645-650.

Anexo 4. Administração de Penicilina G Benzatina em crianças e adolescentes 